\title{
O CONSUMISMO E A GERAÇÃO DE RESÍDUOS SÓLIDOS URBANOS NO BRASIL
}

\author{
Marcos Vinicius Godecke, Roberto Harb Naime², João Alcione Sganderla Figueiredo³ \\ ${ }^{1}$ Universidade FEEVALE RS, mgodecke@yahoo.com.br \\ ${ }^{2}$ Doutor, Professor no Programa de Pós-Graduação em Qualidade Ambiental na Feevale (RS), rnaime@feevale.br \\ ${ }^{3}$ Doutor, Professor no Programa de Pós-Graduação em Qualidade Ambiental na Feevale (RS), sganfigue@feevale.br \\ http://dx.doi.org/10.5902/223611706380
}

\section{RESUMO}

Utilizando pesquisa bibliográfica e documental, este artigo investiga uma das características culturais predominantes nas sociedades contemporâneas, a busca da satisfação através do consumo exagerado de bens, associada às consequências ambientais pela ampliação na geração de resíduos sólidos urbanos. Contextualiza a situação atual e os instrumentos de políticas aplicáveis à minimização na geração desses resíduos no Brasil. Conclui que a combinação de instrumentos de comando e controle, econômicos e de comunicação permite melhorias, desde que a gestão de resíduos urbanos seja percebida de forma sistêmica e holística.

Palavras-Chave: consumo; consumismo; resíduos sólidos urbanos; gestão de resíduos urbanos; minimização.

\section{ABSTRACT}

Using bibliographic and documentary research, this article investigates one of the predominant cultural characteristics in contemporary societies, the pursuit of satisfaction through the excessive consumption of goods and the environmental consequences associated in the generation of solid waste. Contextualizes the current situation and the policy instruments applicable to minimizing the waste generation in Brazil. The study concludes that improvements are possible with the combination of policy instruments: command and control, economic and the communication, since the municipal waste management is perceived in a systemic and holistic form.

Keywords: consumption, consumerism, municipal solid waste, waste management; minimization.

\section{INTRODUÇÃO}

A população do planeta vem aumentando a passos largos, haja vista que ultrapassamos a marca dos sete bilhões, num crescimento de dois bilhões em apenas 25 anos. Um maior contingente populacional e a concentração em áreas urbanas resultam em ampliação na utilização dos serviços ecossistêmicos, cuja depleção ocorre tanto pela utilização para a produção e consumo, como pelos danos decorrentes do retorno dos resíduos à natureza, após sua utilização pelo homem. 
Rev. Elet. em Gestão, Educação e Tecnologia Ambiental (e-ISSN: 2236-1170

Aspectos econômicos e culturais se associam à questão demográfica para acelerar o ritmo da deterioração dos recursos ambientais. A quantidade de resíduos sólidos produzidos pelas populações guarda relação não só com o nível de riqueza, refletido na capacidade econômica para consumir, mas também com os valores e hábitos de vida, determinantes do grau de disposição para a realização do consumo. É ilustrativa a comparação da cultura americana e japonesa: enquanto os primeiros geram cerca de dois quilogramas de resíduos sólidos urbanos (RSU) por habitante ao dia, os japoneses, também de elevado poder aquisitivo, apresentam comportamentos que resultam numa geração significativamente menor, pouco superior a um quilograma. Os brasileiros, apesar de possuírem renda per capita significativamente menor, ficam próximos aos níveis japoneses (ABRELPE, 2008). Essa simples comparação sinaliza para o alinhamento cultural do Brasil com os maiores níveis de geração de resíduos, quando ponderada a capacidade financeira da sociedade para tal.

No Brasil, como em outros países em desenvolvimento, outros malefícios somam-se à questão ambiental, ocasionados por deficiências na gestão dos resíduos sólidos urbanos (GRU), como as doenças decorrentes da proliferação de vetores causadores de doenças e a emissão desnecessária de gases de efeito estufa, agravadores do aquecimento global.

Através de pesquisa bibliográfica e documental, este estudo busca compreender as causas do comportamento de consumo vigente e as formas de atuação na direção da minimização na geração de RSU. Para tanto, além desta introdução e das considerações finais, o artigo está estruturado em duas seções: a primeira procura contextualizar o consumismo numa abordagem transdisciplinar e a segunda discute instrumentos de políticas que visem atenuar as conseqüências do consumo exagerado no tocante à geração de RSU, com ênfase no caso brasileiro.

\section{DO CONSUMISMO CAPITALISTA AO CONSUMO SUSTENTÁVEL}

O consumo apresenta-se como um objeto de estudo relativamente novo nas ciências sociais, mas de importância crescente pela significação que carrega nos tempos atuais, onde exerce um papel central na vida das pessoas, influenciando suas maneiras de pensar, agir e sentir. É característica da sociedade atual a criação de "necessidades" pela forte atuação de interesses particulares no estímulo dos indivíduos às práticas de consumo. As pessoas acabam por dispender recursos financeiros, muitas vezes onerosos, para comprar as "vantagens" apregoadas pela mídia. Os atos de consumir e descartar ocorrem rápida e sucessivamente, pois sempre há algo mais novo, cuja posse, espera-se, finalmente trará a derradeira felicidade e bem-estar prometidos pela propaganda (KREMER, 2007).

As origens da sociedade focada no consumo, em contraposição às tradicionais, voltadas para o trabalho e à produção, remontam movimentos comerciais ocorridos na Europa a partir do século XV que estimularam a revolução industrial, iniciada em meados do século XVIII. A revolução industrial trouxe consigo o fortalecimento da acumulação de riqueza como um valor fundamental, apoiado na ética protestante, que propiciou a aceitação do modelo.

Brewer (2005 apud KREMER, 2007) percebe a concretização e disseminação da sociedade de consumo em três momentos ao longo do século XX: o primeiro na Europa e Estados Unidos entre 1950 e 1974, onde o crescimento econômico trouxe abundância material e permitiu a ampliação nos tempos destinados ao lazer, utilizados para a aquisição de bens; o segundo, com início no final da década de 1960 e apogeu no início da década de 1980, teve as políticas neoliberais buscando a proteção das escolhas individuais ante as críticas relativas ao consumismo; 
Rev. Elet. em Gestão, Educação e Tecnologia Ambiental (e-ISSN: 2236-1170

o terceiro, a partir da década de 1990, pela globalização do capitalismo e seus efeitos. O fenômeno da globalização provocou uma intensa relação intercultural entre os países, alterando as culturas nativas. Apesar da cultura do consumo estar intimamente ligada ao ocidente e ao capitalismo, foi objeto de incentivo na antiga URSS durante o governo de Stalin, estando presente em regimes ditatoriais como na China contemporânea.

Paradoxalmente, ao tempo em que os meios de comunicação estimulam o consumismo, existe no seio da sociedade uma moral que condena esses atos, levando o consumidor a enfrentar um sentimento de culpa ao dar vazão aos seus desejos de consumo. Autores como Campbell (2001) acreditam que esse sentimento inibidor do consumo refletiu-se na produção acadêmica, levando-a a enfatizar nos estudos o lado da produção na economia e negligenciar a pesquisa científica relativa ao consumo. Porém, sob o ponto de vista ambiental, percebeu-se o deslocamento do eixo da discussão, tradicionalmente voltada à ótica da produção decorrente do modelo econômico capitalista, para os padrões de consumo e seus impactos (PORTILHO, 2003).

Nas ciências econômicas a percepção do consumo e suas consequências ambientais apresentou momentos distintos. De um papel de destaque nos primórdios do pensamento econômico, pela valorização dos recursos naturais como fator de produção e na preocupação com sua escassez em face do crescimento populacional, perdeu importância ao longo do século XX, na evolução do mainstream, a teoria neoclássica, pela predominância da concepção dos recursos naturais como abundantes e gratuitos, facilmente substituíveis pelo progresso técnico.

A partir dos debates sobre os limites do crescimento, ocorridos nos anos 1970, o capital natural foi gradualmente resgatado pela teoria neoclássica, através de ramos neoclássicos como a "economia dos recursos naturais" e "economia ambiental" (ENRÍQUEZ, 2010 e THOMAS; CALLAN, 2010). Mais recente, a "economia ecológica" trabalha os mesmos temas, porém com uma visão ecossistêmica e interdisciplinar (ROMEIRO, 2010). Na teoria neoclássica o estudo das escolhas de consumo dos indivíduos está no escopo da "teoria do consumidor". Outra escola econômica, a "institucionalista", amplia o espectro da análise, buscando a explicação para o comportamento dos indivíduos e sua evolução no ambiente institucional a que estão inseridos (FELDMANN, 2008). Os pressupostos da "teoria do consumidor" também foram ampliados pela "psicologia econômica", na incorporação de aspectos subjetivos, emocionais e cognitivos (AZEVEDO, 2009).

Principalmente a partir da década de 1970, as discussões no âmbito das ciências econômicas acompanharam o debate mundial sobre a responsabilização dos estilos de vida e práticas de consumo para os problemas ambientais globais, que culminaram com a conferência Rio92 e seus documentos, a Agenda 21, Declaração do Rio e Tratado das Organizações Não Governamentais (ONG). A Declaração do Milênio, firmada por chefes de Estado durante a Cúpula do Milênio - ano 2000 - estabeleceu metas de referência para a proteção dos recursos naturais, que passaram a referenciar planos de ação nacionais e internacionais como o apresentado na Cúpula Mundial sobre Desenvolvimento Sustentável, realizada em Joanesburgo no ano de 2001, voltado à América Latina e Caribe.

A preocupação com as consequências dos estilos de vida, somada ao ambientalismo público surgido na década de 1970 e à ambientalização do setor empresarial, ocorrida na década de 1980, formaram a base para o surgimento do "consumo verde", onde o consumidor passou a considerar a variável ambiental nos atos de consumo, como forma de influir sobre as matrizes energéticas e tecnológicas do sistema de produção. Enfatizou a reciclagem, o uso de tecnologias limpas, a redução do desperdício e o incremento de um mercado verde. Aspectos como a redução do consumo, a descartabilidade e obsolescência programada, além da desigualdade no acesso aos 
Rev. Elet. em Gestão, Educação e Tecnologia Ambiental (e-ISSN: 2236-1170

bens materiais, foram paulatinamente incorporados ao debate, moldando uma estratégia mais ampla, do consumo sustentável.

O consumo sustentável passou a enfatizar ações coletivas e mudanças institucionais para a introdução de políticas multilaterais de regulação, tanto no tocante à produção como ao consumo. O meio ambiente deixou de ser relacionado apenas a uma questão de "como" usamos os recursos, para incluir o "quanto" o usamos (PORTILHO, 2003). Apesar da evolução na conscientização para os problemas ambientais, pesquisas de opinião como a Global Environmental Survey (GOES) concluem que existe um significativo distanciamento entre a consciência para o problema e as ações a nível individual. Os cidadãos se mostram verbalmente dispostos a fazer sua parte, mas não percebem a relação de causalidade entre a conduta individual e o problema a nível global. Apesar de segmentos importantes das várias populações consultadas acreditarem que o indivíduo pode fazer a diferença para ajudar o meio ambiente, esperam que os governos assumam a liderança, através de medidas regulatórias e rigorização da fiscalização ambiental. Paradoxalmente, tendem a reprovar políticas ambientais que venham a promover alterações significativas nos seus estilos de vida (ESTER et al., 2004). A predisposição dos indivíduos para condutas pró-ambiente também está associada a traços de personalidade, conforme demonstram pesquisas ligadas à psicologia econômica, como a realizada por Hirsh e Dolermana (2007), cruzando valores com tipos de personalidade.

Qual seria, então, a melhor forma de atuação no sentido da redução do consumismo? Tanto a interpretação de pesquisas como a GOES, como aquelas de aspectos subjetivos, a exemplo de Hirsh e Dolermana (2007), parecem corroborar a opinião defendida por Hamilton (2009) de que, mais eficiente que buscar a conscientização dos consumidores compulsivos através da apresentação de fatos relativos à degradação ambiental, na esperança de que a racionalidade prevaleça, é pedir-lhes uma reflexão sobre se seus estilos de vida, de ênfase no consumo, os fazem realmente felizes. Segundo aquele autor, em países ricos largas maiorias acreditam na necessidade de uma mudança radical em suas vidas. Pesquisas da Widmeyer Research and Polling apontam que nove a cada dez americanos percebem sua sociedade como muito materialista, de excessiva ênfase nas compras. O apelo pela "vida rica", em vez da "vida de rico", pode ser mais eficaz para a redução do consumo e à proteção ambiental.

Embora ainda incipiente, as adesões individuais ao consumo sustentável parece estar em curso. Segundo Hamilton (2009), nos últimos dez anos cerca de um quinto dos adultos na GrãBretanha, Estados Unidos e Austrália disseram "sim" quando perguntados se tinham "reduzido a marcha", tomando voluntariamente a decisão de reduzir renda e consumo. Resta saber se a velocidade da mudança será suficiente para evitar o colapso ambiental.

Ao refletir sobre essa questão à luz das teorias do consumidor e institucionalista, Sanson (2005) conclui que o despertar para as questões éticas resultantes da percepção dos impactos ambientas provocados pelos padrões de consumo podem, em competição com outras, encontrar espaço na mente humana, levando à alterações na atual ética antropocêntrica de consumo e vindo efetivamente regular a vida social, induzindo mudanças nas preferências de consumo. 0 autor compara a situação atual e a velocidade das instituições na promoção das mudanças comportamentais a um carro, dirigido por um motorista míope, rumo a um precipício. A queda, ou não, dependerá da velocidade no momento da frenagem.

O relatório The Limits of Growth (MEADOWS et al., 1972) provocou discussão mundial em torno do tema, ao concluir pela necessidade das nações conterem seus crescimentos sob pena de colapso no sistema econômico mundial. Passados trinta anos, esse relatório teve suas análises atualizadas por Turner (2008). O autor obteve conclusões que corroboraram a tese de que o 
Rev. Elet. em Gestão, Educação e Tecnologia Ambiental (e-ISSN: 2236-1170

sistema global está em uma trajetória insustentável, a menos que haja uma redução substancial e rápida do comportamento de consumo, em combinação com o progresso tecnológico. Num cenário intermediário, encontrou o colapso da economia global ainda no século XXI.

As questões relativas aos RSU - geração, aproveitamento e destinação final - influem diretamente na questão, pois o consumo consciente pode atenuar os impactos do crescimento populacional e o reuso, reciclagem, compostagem e recuperação energética dos resíduos aliviam pressões nas produções industriais e de alimentos, além de possibilitaar reduções na poluição e extração de recursos não renováveis. São, portanto, fundamentais para a reversão da atual tendência de colapso ambiental.

A partir de uma breve introdução à GRU e sua contextualização no atual cenário brasileiro, a próxima seção dedica-se ao estudo de políticas, ações e estratégias implementáveis no país visando a minimização na geração dos RSU.

\section{POLÍTICAS DE MINIMIZAÇÃO NA GERAÇÃO DE RESÍDUOS SÓLIDOS URBANOS APLICÁVEIS AO BRASIL}

A dificuldade dos povos mudarem seus padrões de consumo, entre outros fatores, está provocando impactos ambientais irreversíveis. Basta dizer que nos últimos 40 anos estima-se que o planeta tenha perdido $30 \%$ da sua biodiversidade, com maior impacto nos países tropicais, onde a perda atingiu $60 \%$ da fauna e flora originais (WWF, 2010). Com relação aos RSU, a amplitude dos impactos pode ser depreendida a partir dos volumes de geração, associados ao nível de eficácia da sua gestão e aos malefícios que podem acarretar.

A geração, impulsionada pelos fatores econômicos e comportamentais discutidos na seção anterior, também sofre a influência de fatores populacionais, relativos ao crescimento da população e sua concentração nas áreas urbanas. É ilustrativo o caso da América Latina e Caribe, onde a proporção da população urbana frente à rural passou de 68\% em 1985 para 76\% em 2005. Este movimento, somado ao crescimento populacional, levou a um aumento de $60 \%$ na população urbana da região, nos vinte anos considerados (AIDIS, 2006).

No período de 1980 a 2005, a quantidade de RSU per capita aumentou 29\% na América do Norte, $35 \%$ na OCDE, e $54 \%$ na UE15, acompanhando, de uma forma geral, o produto interno bruto (PIB) dos países (SJÖSTÖM e ÖSTBLOM, 2010). No Brasil não dispomos de séries históricas abrangentes e confiáveis relativas a essa geração ${ }^{1}$, mas publicações recentes deixam claro o problema: a geração anual evoluiu de 53 milhões de toneladas em 2008 para 57 milhões em 2009 (7,7\%); e avançou para 60,8 milhões em 2010 (6,8\%), num crescimento bastante superior ao populacional e acima do PIB no período (ABRELPE, 2010 e 2011).

O nível de eficácia da GRU resulta de um conjunto de interações em cada uma de suas etapas, constantes da figura 1 , com os diversos stakeholders com os quais se relaciona, em cada aspecto: técnico, ambiental, social, etc. Essas interações ocorrem de forma dinâmica, em diversas esferas, da individual à internacional, numa atuação combinada com os outros sistemas urbanos, como transporte, drenagem, água, esgoto, energia e paisagismo. 


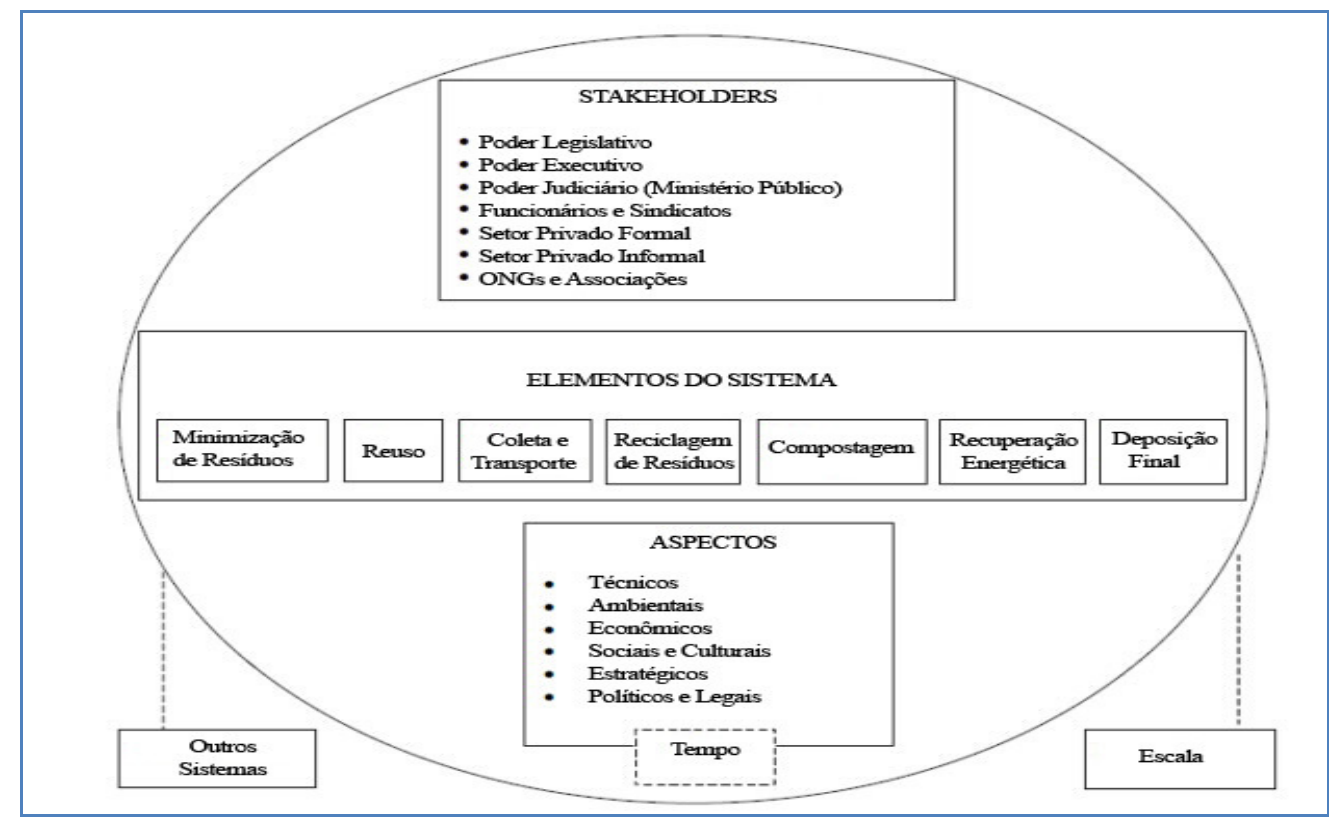

Figura 1 - A GRU Vista de Forma Sistêmica (Fonte: Adaptado de Van de Klundert e Anschiitz (2000))

A baixa eficácia da GRU brasileira fica evidenciada na comparação com países desenvolvidos, a exemplo da Holanda, onde $39 \%$ dos resíduos são reciclados, $7 \%$ são aproveitados pela compostagem e outros $42 \%$ são utilizados para recuperação energética, restando apenas a fração de $12 \%$ para disposição em aterros sanitários (EPE, 2008). No Brasil 11\% dos RSU gerados sequer são coletados. Da parcela coletada, cerca de $43 \%$ são destinados a lixões ou aterros precários (ABRELPE, 2011). Segundo IBGE (2010) essas disposições inadequadas atingem 73,3\% dos municípios brasileiros. Com relação à reciclagem, segundo CEMPRE (2010) a coleta seletiva abrange apenas $8 \%$ dos municípios e $12 \%$ da população brasileira. A nível de recuperação energética, o País possui treze usinas que aproveitam o biogás gerado em aterros sanitários ou por reatores anaeróbicos, somando a capacidade instalada de $70 \mathrm{MW}$ - apenas 0,06\% da matriz de energia elétrica brasileira (MME, 2011).

Entre os principais malefícios decorrentes das destinações finais inadequadas dos RSU estão aqueles que afetam a população de entorno dos locais de deposição dos resíduos sólidos e outros, relativos à saúde humana, poluição ambiental e ao clima. Decorrentes da localização estão o mau cheiro e a depleção paisagística, que resultam em redução no bem-estar das pessoas e na desvalorização dos imóveis de entorno. A saúde humana é impactada pelas doenças transmitidas pelos micro e macrovetores que proliferam nos lixões; pelos malefícios resultantes da absorção de metais pesados provenientes do descarte de lixo eletrônico, pilhas, baterias, lâmpadas fluorescentes, etc; e aquelas decorrentes da poluição do ar, proveniente de particulados e gases cancerígenos emitidos nas incinerações dos resíduos; e ainda pela falta de água e alimentos, decorrentes da redução na capacidade dos recursos naturais em disponibilizar serviços ecossistêmicos. A atmosfera também é impactada pela concentração de gases provenientes da decomposição da matéria orgânica presente no lixo, que agravam o aquecimento do planeta.

A precariedade da situação atual brasileira relativa aos RSU é resultado da conjunção de diversos fatores. Limitações de ordem cultural podem ser depreendidas da pesquisa Instituto Trata Brasil (2009), pela constatação que a maioria da população não associa as condições de saneamento básico à saúde. Barreiras políticas e institucionais ficam aparentes quando tomamos 
Rev. Elet. em Gestão, Educação e Tecnologia Ambiental (e-ISSN: 2236-1170

o exemplo da Lei 12.305/2010, cuja lentidão na tramitação - 19 anos - demonstrou a falta de preocupação da classe política com a questão ambiental e a força obstaculizadora de segmentos empresariais, que visaram evitar ou postergar dispêndios decorrentes da institucionalização do princípio do poluidor-pagador. A expansão da reciclagem esbarra em aspectos ligados ao planejamento dos municípios e aos custos, cerca de quatro vezes maiores que os demandados pela coleta tradicional (CEMPRE, 2010). A baixa penetração das tecnologias de geração de energia a partir dos resíduos decorre de fatores como a falta de uma política de viabilização no Brasil e o baixo nível informacional dos tomadores de decisão sobre alternativas tecnológicas (ROSA et al., 2003). A incineração encontra a forte resistência das entidades ambientalistas e das associações de recicladores, as primeiras pelo receio das conseqüências das emissões gasosas dessas usinas e as últimas pelo temor de perda de mercado com a incineração de recicláveis (AIDIS, 2006).

As deficiências atuais da GRU brasileira, conjugada à percepção dos malefícios decorrentes dessa situação, ensejam a implementação de políticas que atuem em cada "elemento do sistema" apresentado na Figura 1. As ações relativas à minimização da geração de RSU estão na base do sistema, e compreendem as ações ligadas à prevenção, visando a não geração de resíduos; e à redução, nas situações onde a eliminação completa não for possível. Incluem cada indivíduo, através de mudanças nos hábitos de consumo e atitudes; e as empresas, pela redução dos desperdícios com matéria-prima, escolha de materiais para fabricação, racionalização das embalagens e dos processos industriais, etc. A reversão desse quadro implica na mudança de valores arraigados, principalmente nas populações de cultura ocidental, além de sofrer a oposição de interesses particulares, por contrariar a lógica capitalista.

É consenso que a minimização ocupa o topo da hierarquia da GRU, mas não vem recebendo a devida atenção por parte dos planejamentos públicos, que costumam aceitar e projetar o volume atual de resíduos, "esquecendo" de incluir as ações de minimização. Entre as possíveis causas para esta situação pode estar a preferência dos técnicos pelos aspectos mais tangíveis do processo, como coleta, tratamento e disposição dos resíduos; e a dificuldade no estabelecimento de uma relação direta entre os resultados e as ações de minimização, pela diversidade de fatores que atuam na mente do consumidor.

No setor industrial a minimização está bastante presente, pois sua adoção tende a reduzir os custos de produção, favorecendo a lucratividade. A mesma reflexão não se aplica às famílias, por não perceberem facilmente os custos do descarte. Outros fatores também atuam negativamente, como a tendência das famílias ficarem cada vez menores - famílias pequenas descartam proporcionalmente mais resíduos por indivíduo; e maior número de famílias com mais de um imóvel (COOPER, 1999).

As políticas de minimização orbitam, de forma simples ou combinada, em três segmentos: comando e controle (C\&C); instrumentos econômicos; e de comunicação. Nos instrumentos C\&C as instâncias reguladoras estabelecem um conjunto de regras e padrões que devem ser obedecidos pela sociedade, sob pena de incorrer em penalidades. Por sua vez, os instrumentos econômicos visam a internalização das externalidades que não seriam normalmente imputadas ao agente poluidor. Incluem taxas e tarifas, subsídios (subvenções, empréstimos subsidiados, incentivos fiscais) e licenças de poluição comercializáveis, como os certificados de redução de emissões. Os instrumentos de comunicação atuam na conscientização, informação e educação dos agentes poluidores. São exemplos a educação ambiental, a divulgação de benefícios para as empresas que respeitam o meio ambiente e os selos ambientais (LUSTOSA et al., 2003).

Importante iniciativa de C\&C, a Council Directive 99/31/EC (abril de 1999), entre outras resoluções, determinou aos países membros da União Europeia a elaboração de planos para a 
Rev. Elet. em Gestão, Educação e Tecnologia Ambiental (e-ISSN: 2236-1170

redução gradativa dos resíduos biodegradáveis a serem direcionados aos aterros sanitários (UE, 1999). No Brasil, a Lei 12.305/2010 colocou como objetivos da Política Nacional de Resíduos Sólidos a não geração, redução e estímulo à adoção de padrões sustentáveis de produção e consumo de bens e serviços. Na regulamentação desta lei, o Decreto 7.404/2010 atribuiu ao Comitê Interministerial da Política Nacional de Resíduos Sólidos a tarefa de propor medidas que permitam a implementação de instrumentos econômicos e de comunicação como incentivos fiscais, financeiros e creditícios; pesquisa científica e tecnológica; e educação ambiental, esta como atribuição do Setor Público (BRASIL, 2010a e 2010b).

A operacionalização da Lei 12.305 é facilitada pela possibilidade dos municípios se associarem entre si ou com a iniciativa privada, conforme disciplinam as leis 11.079/2004 e 11.107/2005. São muitos os exemplos dessas parcerias em diversos estados brasileiros, principalmente para a construção de aterros sanitários de uso compartilhado. A conveniência da escolha entre os tipos de associação, que vinham sendo discutidas para as obras de saneamento previstas na Lei 11.445/2007, estão sendo ampliadas para o cumprimento dos prazos estabelecidos na Lei 12.305 (BRASIL, 2004; 2005; 2007).

Diferentes instrumentos econômicos podem ser utilizados para a minimização na geração de resíduos. A cobrança pela disposição em aterros é uma forma indireta de inibir a geração dos resíduos, pois atua no final do processo (disposição) para gerar reflexos no seu início (geração). É necessário cuidado na determinação do valor de cobrança, que deve ser suficientemente alto para estimular as medidas de redução, mas não ao ponto de induzir à disposição ilegal. As formas dessa cobrança são bastante variadas, em função da legislação de cada país (CHERMONT; MOTTA, 1996).

Uma forma de cobrança direta pela geração é a taxação dos sacos de lixo vendidos no varejo, diferenciada em função das capacidades de acondicionamento. Além de uma tributação anual fixa por moradia, Zuriche (Suiça) adotou esta cobrança, proibindo a coleta do lixo que estiver acondicionado em outro tipo de saco (CAMARGO, 2009). O sobrepreço dos sacos de lixo induz à minimização e gera receitas para outras iniciativas ligadas à GRU.

Alguns paises adotam sistemas de cobrança por tipo de descarte, de acordo com o princípio do poluidor-pagador, a exemplo da Bélgica no programa Waste Charges; Dinamarca, para embalagens plásticas e de papel; Canadá, sobre material promocional em papel; e Coréia, por classes de produtos, de acordo com tamanho e potencial de dano ambiental. A tributação sobre a venda de produtos que utilizam materiais danosos ao meio ambiente incorpora previamente os custos da coleta e destinação final, incentivando ajustes no comportamento do fabricante e do consumidor, já que o primeiro tende a repassar ao segundo os acréscimos resultantes da tributação. Pode-se taxar simultâneamente a matéria-prima e o produto acabado, acelerando a indução à mudança no consumo, porém essa aplicação deve ocorrer de forma cuidadosa, devido aos problemas da dupla tributação (CHERMONT; MOTTA, 1996).

Sjöström e Östblom (2010) defendem que a introdução de impostos sobre os materiais virgens pode acelerar o desenvolvimento de tecnologias de prevenção de resíduos para as empresas e a aplicação de diferenciações na tributação em favor de bens e serviços pode reduzir a intensidade dos resíduos resultantes do consumo das famílias.

Programas de governo tentam reduzir a geração de resíduos, como o britânico Waste Strategy for England 2007, que pretende alcançar até 2020 uma redução de 45\% nos níveis de geração de resíduos domiciliares,comparativamente aos de 2000 (DEFRA, 2007). O português "Programa Nacional de Prevenção de Resíduos Urbanos" planeja reduzir a coleta em 50 a 100 quilos de lixo por pessoa/ano, atualmente estimada em $470 \mathrm{~kg}$. Implica em redução de 17\% até 
Rev. Elet. em Gestão, Educação e Tecnologia Ambiental (e-ISSN: 2236-1170

2016. Se nada for feito a expectativa é de que ocorra um crescimento na ordem de $4 \%$ (GARCIA, 2009).

Visando a sustentabilidade ambiental através da mudança nos padrões de produção e consumo, os países da América Latina e Caribe deram prosseguimento à Conferência de Joanesburgo, sendo que na XIV Reunião de Ministros de Meio Ambiente da região, realizada no Panamá em 2003, no tocante à minimização apresentaram recomendações para a utilização de instrumentos de comunicação, tais como o apoio a projetos voltados ao combate da "cultura do desperdício", dirigidos a sociedade, englobando questões relativas ao uso racional de recursos naturais (água, energia e matérias-primas) e redução de resíduos; a inclusão do tema na educação fundamental, de modo a promover uma mudança cultural nas gerações futuras; e sua incorporação nas políticas nacionais e regionais, com a identificação de prioridades para a atuação (PNUMA, 2004).

Apesar do alto custo do serviço de coleta dos RSU no Brasil, estimado em R\$ 7 bilhões no ano de 2010 - equivalente a R\$ 3,71 por habitante/mês - que absorve parcela significativa dos orçamentos municipais ${ }^{2}$, muitos municípios brasileiros sequer cobram pelo serviço (ABRELPE, 2011). Nos municípios onde é cobrada, a taxa pelo serviço de recolhimento de lixo costuma vir agregada ao Imposto Predial e Territorial Urbano (IPTU), de peridiocidade anual, fixada através de critérios genéricos como o tamanho e a qualidade das construções ou o tamanho das famílias. Essas fórmulas não estimulam a redução na geração de resíduos, por não apresentarem nexo causal entre o esforço da minimização e o pagamento pelo serviço.

A falta de recursos para a GRU, além de estimular a destinação inadequada pela má qualidade na prestação do serviço, canaliza os esforços institucionais para ações emergenciais como a eliminação dos lixões, deixando em segundo plano ações importantes como às de minimização. $O$ atual estágio de desenvolvimento da GRU brasileira, de políticas voltadas para a melhoria de aspectos primários da gestão, desincentivam a discussão sobre a aplicação de instrumentos econômicos como a cobrança direta por peso do lixo recolhido, defendida por Valério et al. (2008).

É perfeitamente factível ao Brasil a elaboração de planos de ação para o estímulo ao consumo consciente e à redução na geração dos resíduos, amplamente utilizados em outros países, com a adoção de metas e definição de prioridades de atuação, pensando-se na aplicação de instrumentos econômicos para o estímulo e premiação às condutas ambientalmente sustentáveis.

O fato das mudanças culturais se mostrarem lentas e difíceis de dirigir não deve servir de desestímulo às ações como campanhas educativas apoiadas por legislações e à implementação de instrumentos econômicos, que possam atuar sobre a consciência ambiental da população, resultando em consumo consciente e minimização da geração de resíduos urbanos.

\section{CONSIDERAÇÕES FINAIS}

Na medida em que as conseqüências ambientais dos modelos voltados inteiramente ao crescimento econômico ficaram progressivamente visíveis, surgiram, principalmente a partir da década de 1970, preocupações quanto à capacidade do planeta em suportar a manutenção do bem-estar das gerações futuras, mantida a forma antropocêntrica atual na relação com os serviços ecossistêmicos. 
Este estudo buscou elementos para a reflexão sobre a atual forma predominante de consumo, insustentável sob a ótica ambiental, e a significância dos movimentos na direção contrária, do consumo verde e do consumo sustentável. Embora esteja em curso um processo de conscientização coletiva sobre a necessidade de uma mudança significativa nos hábitos de consumo, a velocidade da mudança nas atitudes, tanto à nível de governos, empresas e pessoas, está muito aquém da necessária. Apesar da consciência para a questão, poucos a efetivam em suas ações, menos ainda com a profundidade necessária. Como não há disposição para mudanças voluntárias, as instituições precisariam estar dispostas a agir coercitivamente, através da combinação de instrumentos legais, com outros de natureza econômica e de comunicação.

O consumismo estimula indiretamente a depleção ambiental ao aumentar desnecessariamente a extração na natureza dos insumos utilizados nos processos de produção. $E$ diretamente, ao devolver ao meio ambiente volumes de resíduos em quantidades superiores às que ocorreriam numa situação de consumo consciente. A conseqüente redução da capacidade ambiental para a prestação dos serviços ecossistêmicos vai paulatinamente reduzindo o bem-estar social, pelas doenças, extremos climáticos, perdas na produção de alimentos, disponibilização de água, etc.

Antes da preocupação com a destinação correta dos resíduos, visando à redução de efeitos nocivos da disposição final inadequada, ou o seu desejável reaproveitamento via reuso, reciclagem, compostagem e recuperação energética, os maiores esforços deveriam estar nas ações visando a não geração de resíduos.

Este texto elencou inúmeras alternativas de políticas para esta minimização aplicáveis ao Brasil. Com a publicação da Lei 12.305 o País alinhou-se na direção das melhores práticas de GRU, porém a preocupação que se apresenta guarda paralelo com a questão do consumo: a velocidade das mudanças. No âmbito da minimização seria muito bem vindo um plano nacional com o estabelecimento de metas de redução na geração de resíduos, discutidas no seio da sociedade, conjuntamente com o "o que" e o "como" fazer. À definição da combinação de instrumentos C \& C, econômicos e de comunicação, seguiria sua implementação pelas instituições.

Vasta gama de melhorias podem ser discutidas e implementadas, desde que a GRU seja percebida de forma sistêmica e holística. Um bom começo seria a implementação das recomendações resultantes de PNUMA (2004), por serem de operacionalização imediata, desde que haja disposição política para tal. Meios de comunicação de massa podem ser utilizados para campanhas de conscientização da população. Esta não seria novidade, pois na década de 1970 tivemos a campanha do personagem Sugismundo e seu slogan "povo desenvolvido é povo limpo". Entre as muitas ações viáveis está a capacitação de jovens carentes como agentes ambientais, para atuarem como multiplicadores em suas comunidades.

O equacionamento dos problemas relativos aos resíduos é de difícil solução justamente por guardar relação direta de causa e efeito com as insustentáveis práticas de consumo, arraigadas na sociedade contemporânea.

\section{REFERÊNCIAS BIBLIOGRÁFICAS}

ASOCIACIÓN INTERAMERICANA DE INGENIERÍA SANITARIA Y AMBIENTAL (AIDIS). Directrices para la Gestion Integrada y Sostenible de Residuos Solidos Urbanos en America Latina y el Caribe. São Paulo, 2006. 118 p. Disponível em: <www.polis.org.br>. Acesso em: 22 nov. 2008. 
ASSOCIAÇÃO BRASILEIRA DE EMPRESAS DE LIMPEZA PÚBLICA E RESÍDUOS ESPECIAIS (ABRELPE). Panorama dos resíduos sólidos no Brasil 2007. São Paulo, 2008. Disponível em: <www.abrelpe.org.br/panorama_2007.php>. Acesso em: 22 abr. 2010.

Panorama dos resíduos sólidos no Brasil 2009. São Paulo, 2010. Disponível em: <www.abrelpe.org.br/panorama_2009.php>. Acesso em: 22 abr. 2010.

Panorama dos resíduos sólidos no Brasil 2010. São Paulo, 2011. Disponível em: <www.abrelpe.org.br/panorama_2010.php>. Acesso em: 22 abr. 2010.

AZEVEDO, P. R. Consumo sustentável: possibilidade de equilíbrio entre teoria neoclássica e psicologia econômica. PPG em Economia - PUCRS, Porto Alegre, 2009. 84 p.

BRASIL. Decreto no 7.404, de 23 de dezembro de 2010. Regulamenta a Lei no 12.305, de 2 de agosto de 2010, e dá outras providências. Diário Oficial da União, Brasília, 23 dez. 2010, Edição Extra. b

. Lei no 11.079, de 30 de dezembro de 2004. Institui normas gerais para licitação e contratação de parceria público-privada no âmbito da administração pública. Diário Oficial da União. Brasília, 31 dez. 2004.

. Lei no 11.107, de 06 de abril de 2005. Dispõe sobre normas gerais de contratação de consórcios públicos e dá outras providências. Diário Oficial da União. Brasília, 7 abr. 2005.

. Lei no 11.445, de 05 de janeiro de 2007. Estabelece diretrizes nacionais para o saneamento básico; e dá outras providências. Diário Oficial da União. Brasília, 8 jan. 2007, e retificado no DOU de 11 jan. 2007.

. Lei no 12.305, de 2 de agosto de 2010. Institui a Política Nacional de Resíduos Sólidos; e dá outras providências. Diário Oficial da União. Brasília, 3 ago.2010. a

CAMPBELL, C. A ética romântica e o espírito do consumismo moderno. Mauro Gama (trad.). Rio de Janeiro: Rocco, 2001.

CAMARGO, S. Zurique é modelo em reciclagem de lixo. Planeta Sustentável. Notícia Eletrônica. 11 maio 2009. Disponível em: <planetasustentavel.abril.com.br/noticia/lixo/conteudo_467362.shtml>. Acesso em: 30 jul. 2009.

CHERMONT, L. S.; SEROA DA MOTTA, R. Aspectos Econômicos da Gestão Integrada de Resíduos Urbanos. Texto para Discussão no 416. Instituto de Pesquisa Econômica Aplicada (IPEA). Maio de 1996. Disponível em: <www.cipedya.com/doc/100336> Acesso em: 29 maio 2011.

COMPROMISSO EMPRESARIAL PARA RECICLAGEM (CEMPRE). Pesquisa CICLOSOFT 2010. Disponível em: <www.cempre.org.br> . Acesso em: 11 abr. 2010. Homepage institucional.

COOPER, J. Waste Minimization and Recycling: choosing the best practicable options for solid waste management. In: ISWA Annual Congress 1999. Ategrus XXV Anniversary Conference. Oviedo, Espanha. 2628, maio 1999. Anais eletrônicos... Oviedo.

DEPARTMENT FOR ENVIRONMENT FOOD AND RURAL AFFAIRS (DEFRA). Waste Strategy for England 2007. Disponível em: <http://www.official-documents.gov.uk/document/cm70/7086/7086.asp>. Acesso em: 15 maio 2011.

ENRÍQUEZ, M. A. Economia dos Recursos Naturais. In: MAY, P. H. (org.). Economia do Meio Ambiente: Teoria e Prática. 2a ed. Rio de Janeiro: Elsevier, 2010. p.49-78.

EMPRESA DE PESQUISAS ENERGÉTICAS (EPE). Nota Técnica DEN 06/08 : Avaliação Preliminar do Aproveitamento Energético dos Resíduos Sólidos Urbanos de Campo Grande, MS. EPE. Rio de Janeiro, 2008. $37 \mathrm{p}$.

ESTER et al. Cultural change and environmentalism: a cross-national approach of mass publics and decision makers. Revista Ambiente e Sociedade, São Paulo, vol. 7, n. 2, 2004. 
Rev. Elet. em Gestão, Educação e Tecnologia Ambiental (e-ISSN: 2236-1170

FELDMANN, H. O comportamento de consumo do adolescente e a Teoria do Consumidor. PPG em Economia - Universidade Federal do Rio Grande do Sul, Porto Alegre, 2008. 185 p.

GARCIA, R. Governo lança programa para reduzir lixo urbano. Público.PT. Disponível em: <ecosfera. publico.pt/noticia. aspx?id=1385073>. Acesso em: 29 jul. 2009.

HAMILTON, C. Consumerism, self-creation and prospects for a new ecological consciousness. Journal of Cleaner Production, v.18, issue 6, p. 571-575, 2010.

HIRSH, J.B.; DOLDERMANA, D. Personality predictors of Consumerism and Environmentalism: A preliminary study. Personality and Individual Differences, v.43, Issue 6, pages 1583-1593, 2007.

INSTITUTO BRASILEIRO DE GEOGRAFIA E ESTATíSTICA (IBGE). Pesquisa Nacional de Saneamento Básico 2008. IBGE, Rio de Janeiro, 2010. 219 p.

INSTITUTO TRATA BRASIL. Percepções sobre saneamento básico. Pesquisa. IBOPE. 12 ago. 2009. Disponível em: <tratabrasil.org.br/novo_site/cms/APRESENTACAO_IBOPE_TRATA/Apresentacao_coletiva_12ago.pdf>. Acesso em: 18 out. 2009.

KREMER, J. Caminhando rumo ao consumo sustentável: uma investigação sobre a teoria declarada e as práticas das empresas no Brasil e no Reino Unido. PPG em Ciências Sociais. PUCSP, São Paulo, 2007. 323 p.

LUSTOSA et al. Política Ambiental. In: May et al. (org.). Economia do Meio Ambiente: teoria e prática. Rio de Janeiro: Elsevier, 2003, 6a reimpressão. p.135-154.

MEADOWS, D. H. et al. Limites do Crescimento. Coleção Debates. São Paulo: Editora Perspectiva S.A., 1973, $203 p$.

MINISTÉRIO DAS MINAS E ENERGIA (MME). BIG - Banco de Informações de Geração. Agência Nacional de Energia Elétrica (ANEEL). 2011.2011 Disponível <aneel.gov.br/aplicacoes/capacidadebrasil/OperacaoCapacidadeBrasil.asp>. Acesso em: 11 abr. 2011.

PROGRAMA DAS NAÇÕES UNIDAS PARA O MEIO AMBIENTE (PNUMA). A produção mais limpa e o consumo sustentável na América Latina e Caribe. CETESB\Secretaria de Meio Ambiente do Governo de São Paulo. Publicação das Nações Unidas, São Paulo, 2004. 120 p.ISBN:92-807-2499-1.

PORTILHO, F. ConsumoVerde, Consumo Sustentável e a Ambientalização dos Consumidores. 2003. Disponível em: <uff.br/lacta/publicacoes/artigoFatimaPortilho.doc>. Acesso em 13 mar.2011.

ROMEIRO, A. R. Economia ou Economia Política da Sustentabilidade. In: MAY, P. H. (org.). Economia do Meio Ambiente: Teoria e Prática. 2a ed. Rio de Janeiro: Elsevier, 2010. p.3-32.

ROSA et al. Geração de Energia a Partir de Resíduos do Lixo e Óleos Vegetais. In: TOLMASQUIM, M. T. (org.). Fontes Renováveis de Energia no Brasil. Rio de Janeiro: Interciência : CENERGIA, 2003. p.93-161.

SANSON, J.R. Ethics, Politics, and Nonsatiation in Consumption: A Synthesis. In: 33o Encontro Nacional de Economia, 6 - 9 dez. 2005, Natal (RN). Anais eletrônicos... Natal.

SJÖSTRÖM, M.; ÖSTBLOM, G. Decoupling waste generation from economic growth - A CGE analysis of the Swedish case. Ecological Economics, v. 69, Issue 7. 15 May 2010, p.1545-1552.

THOMAS, J. M.; CALLAN, S. J. Economia Ambiental : aplicações, políticas e teoria. São Paulo : Cengage Learning, 2010. $556 \mathrm{p}$.

TURNER, G. A Comparison of "The Limits to Growth" with Thirty Years of Reality. Commonwealth Scientific and Industrial Research Organisation (CSIRO). CSIRO Working Paper Series 2008-09, Australia, June 2008, 49 p. ISSN: 1834-5638. 
UNIÃO EUROPÉIA. COUNCIL DIRECTIVE 1999/31/EC of 26 April 1999 on the landfill of waste. Disponível em: <eur-lex.europa.eu/LexUriServ/LexUriServ.do?uri=CONSLEG:1999L0031:20081211:EN:PDF>. Acesso em: 14 maio 2011.

VALÉRIO, D. et al. Redução da Geração de Resíduos Sólidos: uma Abordagem Econômica. 360 Encontro Nacional de Economia, 9 - 12 dez. 2008, Salvador (BA). Anais eletrônicos... Salvador.

VAN DE KLUNDERT, A.; ANSCHIITZ, J. The Sustainability of Alliances Between Stakeholders in Waste Management. Working paper for UWEP/ CWG, 30 May 2000 - Draft. Disponível em: <gdrc.org/uem/waste/ISWM.pdf>. Acesso em: 13 mar. 2009.

WORLD WIDE FUND FOR NATURE (WWF). Relatório Planeta Vivo 2010. Out. 2010. Disponível em: <wwf.org.br/informacoes/bliblioteca/?26162/Relatrio-Planeta-Vivo-2010>. Acesso em: 01 maio 2011.

\section{NOTAS}

1. O Instituto Brasileiro de Geografia e Estatística (IBGE) realizou levantamentos relativos ao saneamento básico brasileiro nos anos de 1974, 1977, 1989, 2000 e 2008, porém a falta de padrão metodológico impede comparações diretas dos resultados obtidos (IBGE, 2010).

2. Mais $R \$ 12$ bilhões para outros serviços como varrição, capina, limpeza e manutenção de parques e jardins, limpeza de córregos, destinação final, etc.. (ABRELPE, 2011). 